\title{
Africa Vidal y Javier Franco (eds) 2009. A (Self-) Critical Perspective of Translation Theories Una visión (auto)crítica de los estudios de traducción. ( = Monografías de Traducción e Interpretación 1). Universidad de Alicante, Universitat Jaime I and Universitat de Valencia. ISSN 1889-4178
}

Javier Franco Aixelá, co-editor of Monographs in Translation and Interpreting, MonTI, devotes the introduction - written in English, Catalan, French, German, and Spanish - to presenting this electronic and printed academic journal as a collaborative project of three Spanish public universities: The universities of Alicante, Jaume I and Valencia, each of which offers a degree in Translation and Interpreting in the Valencia Region. In order to position itself in the academic world - there are many journals devoted to translation and interpreting in Spain and elsewhere - Franco Aixelá describes the essential characteristics of the journal: internationalism; plurality; rigour; and internal democracy.

By internationalism is meant that articles will be published in Catalan, English, French, German, and Spanish. He also indicates that, whenever possible, the electronic version of the journal will include a translation in English of the articles which were not originally written in English. Plurality and rigour go hand in hand. Both will ensure the publication of articles coming from research centres other than the three founding universities, that guest editors will be invited to edit each issue, and that the process of reviewing each article will follow known academic standards and practices: the list of referees and advisors includes well-known scholars from all over the world. Finally, internal democracy means that the members of the Managing Board, all of whom are academics working in the three founding universities - will be appointed on a rotating basis. Time will inform us whether the above principles will lead this journal into academic excellence. This initial volume partly agrees with them. On the one hand, the volume has articles by scholars from different places (Spain, Germany, France, the United States, and the United Arab Emirates), written in different languages (i.e., there are 8 articles in English and one in Spanish; two of the reviews are in English, and two more in Catalan) that analyse issues such as literary translation, terminology, translation theory, interpreting, and the elusive nature of meaning from different perspectives. On the other hand, the volume does not offer new research; rather, it summarises known views in the field of Translation Studies.

In "Rethinking Translation in the $21^{\text {st }}$ Century" and its Spanish translation "A vueltas con la traducción en el Siglo XXI" (pp. 39-58), Africa Vidal Claramonte reviews changes in the concept of translation, which has gone from absolute equivalence to unforeseen limits. She explains the changes undergone by the same concept of translation by indicating that translation reflects the kind of society which produces it. Today's culture is characterised by being contradictory, hybrid, and enriched thanks to migration. These three traits are also underlying today's translation theory that must make room for accomodating cross-cultural clashes. She adds that given the current situation and the fact that we are living in a globalised world, translators are expected to "find the most appropriate association for the local and the global, for the Self and the Other, through specific cultural experiences which are also related to what is alien, unknown and different to us" (Cronin 2006: 3). This dual nature is influencing translation and will also be of the utmost importance in the foreseeable future considering that translation must confront globalisation - and its corollary of blurred frontiers, diffuse barriers, and harmonization - with particularisation:

\footnotetext{
Nowadays, in the era of globalization, the translator seems to understand very clearly that the idea of "universal” [sic] words such as "die”, "live”, "star", "swim”, and even ubiquitous artifacts like "mirror" and "table", which are not problematic from the point of view of translation (Newmark 1988: 94), is impossible (Fernández González 2008: 45).
}

Legal translation - it has experienced a lot of changes following the Critical Legal Studies, the Feminist Jurisprudence or the Critical Race Theory - illustrates some of the main challenges facing translators within the theoretical scenario characterised by the existence of dual forces at 
work. In the end, she finishes optimistically: changes must be always subjected to the core values of integrity, responsibility, fidelity, boldness, and humility.

Olga Castro analyses the role of feminism in Translation Studies in her paper titled "(Re)examinando horizontes en los estudios feministas de traducción: ¿Hacia una tercera ola?” (pp. 59-86) (Eng: (Re)examining horizons in feminist Translation Studies: towards a third wave?). She starts by presenting some of the main theses of the Feminist Translation School developed in Canada that are still regarded as the paradigm of interaction between feminism and translation. Moving on, Olga Castro aims at both advancing new approaches to the practice of translation and paratranslation from a feminist perspective and opening new debates by means of reexamining topics of mutual interest for both Translation Studies and Feminism on a conceptual, historical, and critical plane. Castro claims that the Canadian paradigm that shows the interplay between Feminism and Translation must be abandoned and substituted by new approaches that take into consideration conceptual, historiographic, critical and practical views.

The conceptual view starts by reviewing some of the gender metaphors (for example "les belles infidèles) commented on in Translation Studies (the concept of gender metaphors has also been analysed as a powerful ideological tool in the discourse of advertising. See Velasco-Sacristán/ Fuertes-Olivera 2006). The conclusion drawn is obvious: Translation Studies must shy away from this gendered tradition and put in place new concepts that highlight feminist points of view. Venuti (2008), for example, claims that translation can become "a cultural means of resistance against multinational capitalism and the political institutions to which the current global economy is allied" (p. 69). The historiographic view defends the construction of a feminist approach to history by bringing into the fore of translation studies the works of female authors (translators and theorists) who have been mostly neglected in the (Western) canon. Finally, the critical approach defends a feminist critique of translations that go against "phallotranslators, inadequate interpreters of women's writing, given an observable reliance on engrained phallocentric assumptions." (Henitiuk 1999: 473). Finally, the practical approach is presented as a way of showing the feminist process of translation. In particular, she claims the necessity of examining within Translation Studies the "third wave feminist linguistics" proposed by Mills (2008).

Lea Cyrus presents the development of the translation shift concept in "Old Concepts, New Ideas: Approaches to Translation Shifts” (pp. 87-106). A translation shift indicates the existence of divergence between a source and a target text, and there have been several attempts to develop a classification system for them. The origin of the translation shift concept is placed in the linguistics-oriented era of translation studies, and its interest in level shift, category shift, transposition, modulation, equivalence, adaptation, additions and substractions, alterations, modification, and mutation. Although by the mid 1990s, the preponderantly linguistic approaches to translation were replaced by the cultural oriented branch of descriptive translation studies, we are witnesses to a renaissance of linguistic approaches in connection with the "corpus-assisted analysis of shifts", and the use of the shift approach for measuring freeness, annotating shifts, and evaluations of machine translation. All these new approaches owe a lot to Leuven-Zwart's pioneering model used for the description of actual translations rather than of the relationship between two linguistic systems.

Corpus-assisted analysis of shifts is mostly devoted to highlighting the general texture of the two texts, usually by collecting basic word statistics, calculating type-toke ratios and shifts in lexical cohesion, etc. The shift approach is also used to investigate current norms with respect to different degrees of freeness in the translation of different text types, "which will influence the way an automatic word-alignment tool will work on these texts" (p. 99). Macken (2007), for example, has shown that the three text types that she studied differ with respect to the degree of literalness, which suggests that different norms have been applied in their translation. Cyrus (2006) introduces a small-scale manual annotation projec that focuses on the annotation and categorisation of translation shifts through predicate-argument structures. Ahrenberg/Merkel (2000) "propose a correspondence model based on structural and semantic shifts, which can be used for the linguistic evaluation of 
machine translation output" (p. 102). This approach is interesting in that it acknowledges the fact that shifts are "parts and parcel of high-quality translations and must not be mistaken for errors" (Ahrenberg/Merkel 2000: 103).

Pamela Faber offers a critical analysis and overview of terminology theories in "The Cognitive Shift in Terminology and Specialized Translation" (pp. 107-134). She claims that the study of specialised language is undergoing a cognitive shift, which is conductive to a greater emphasis on meaning as well as conceptual structures underlying texts and language in general. This cognitive shift is present in the fact that terminology theories are evolving from prescriptive to descriptive with a growing focus on the study of specialized units from a social, linguistics and cognitive perspective. Consequently, she defends that the translation of specialised texts requires both expert and linguistic knowledge. Following this idea, I will add that translators of specialised texts need reference terminological works that cater for both their cognitive and communicative needs. It is true that she acknowledges the fact that terminology has arisen due to practical needs, but these practial needs that crop up in a known user situation (translators who are translating specialised texts) are not discussed at all in the paper, perhaps because her point of departure is limited to what she thinks terminology is - "a linguistic and cognitive activity" (p. 109) - and she does not pay attention to the practical nature of terminology that is the production and construction of specialised dictionaries, glossaries, thesauri, knowledge databases, etc., demanded by the potential users here implied: translators of specialised texts.

The critical description offered of different terminology theories - she mentions Wüster's General Terminological Theory (GTT), Gaudin and colleagues' Socioterminology, Cabré's Communicative Theory of Terminology (CTT), and Temmerman's Sociocognitive Terminology - forms the basis of frame-based terminology, a new proposal by Faber and colleagues (Faber et al. 2005, 2006) that focuses on: (1) conceptual organization; (2) the multidimensional nature of terminological units; (3) the extraction of semantic and syntactic information through the use of multilingual corpora; and (4) the virtue of dealing with the role of images in the representation of specialised concepts, whenever possible. I have not come across a terminological product (for example a specialised dictionary - that has been constructed by applying the above principles systematically and consistently, which makes me unsure of the merits of the proposal made. What Faber offers as an illustration of frame-based terminology - she calls it the coastal engineering event - is of limited help when translating specialised texts.

The historical evolution of interpreting is discussed by Daniel Gile in "Interpreting Studies: A Critical View from Within” (pp. 135-155). Interpreting started as a profession-driven, narrowfocused independent discipline that acquired the status of an academic discipline in the second half of the $20^{\text {th }}$ century, especially thanks to the works of Seleskovitch at ESIT (Paris). The ideas developed by Seleskovitch and others started to wane in the 1990s due to three main factors: internal pressure, environmental stimulation, and self-limitation within the 'theory of sense' paradigm (p. 138). Instead, since the 1990s, interpreting research has entered into university departments and has started to be strongly influenced by cognitive science, "especially cognitive psychology and neurolinguistics” (p. 139) and linguistics, to establish meaningful links with translation scholars, and to be redefined by scholars outside conference interpreting who, for instance, have widened the scope of research by exploring "working conditions, the communication process during interpreting, professional qualifications, role perceptions and the effect of the interpreter's intervention on the parties concerned" (p. 141).

A critical look from within allows Gile to evaluate the current situation of interpreting. Firstly, he claims that interpreting should not be viewed within the narrow sense of scientific disciplines but as an academic activity that has provided interpreter trainers with "conceptual frameworks around which to structure their ideas and teaching activities" (p. 142-143). Secondly, interpreting has objective limitations, especially because the number of active researchers is small which has qualitative implications. For example, the quality of the works published cannot always be assessed 
very strictly, Gile adds that the "main problem in the academic literature of IS is that too many of its publications do not comply with academic norms other than academic writing" (p. 143). Some of the problems he mentions are: weak or inexistent references to the existing literature on the subject; misrepresentation of the literature when it is quoted; incorrect comprehension as to use of concepts; inadequate methodologies; overgeneralizations and inferencing errors. These weaknesses are explained by environmental and human factors: most interpreters are professsional interpreters and not professional researchers who have no time to consult existing literature in depth, have difficult access to naturalistic data, and have not been trained in doing research. In spite of these weaknesses, Gile looks towards the future more optimistically due to its current association with Translation Studies, and to recent theories and paradigms developed from within (for example, Chernov 2004). In order to follow this path, Gile finishes his paper by suggesting a stronger twoway interaction between traslation and interpreting research, and by defending the adoption of humble and strict measures regarding training for both professional and research purposes.

Hermeneutics investigations with its emphasis on the role of the translator as co-creator of the text is the object of interest in Amrollah Hemmat's contribution "Contemporary Hermeneutics and the Role of the Self in Translation" (pp. 157-174). He indicates that the translator moves beyond the limitation of the traditional philology "and steps into the realm of hermeneutics, leaving the ethic mode and adopting an emic perspective. In doing so, the translator's self plays a role in the process of translation which raises concerns for fidelity to the originl text” (p. 159). To overcome such concerns of subjectivity, the only cure is reflexivity that forces translators to be aware of and to acknowledge the role which his or her self plays in defining and interpreting the text. In sum, the translator needs to "deconstruct and reconstruct the translated work through a "recursive hermeneutic process" (Steiner 1995: 78) in order to achieve the maximum possible level of fidelity to the text” (p. 164). Within this theoretical framework secondary or modern philology (Becker 2000: 137) must abandon the objective of interpreting the text in itself (the concern of traditional or primary philology) for concentrating on hermeneutics with its interest in asking context questions. For example, the "double bind" theory (Bateson 1972) can help us understand the translation process presented by Steiner as bridge building.

The nature of meaning, emphasising the associative character of lexical meanings, is the object of analysis of Nida's "Understanding the Meaning” (pp. 175-182). Nida indicates that poorly "written texts are the most serious obstacle to effective translating” (p. 177). In particular, he mentions texts in which the terminology is strange, the grammar is obscure, and which are full of mantras.

Regarding terminology, Nida favours the activities taken by terminologists in the European Union who "no longer attempt to define the various meanings of words and phrases. Instead, they provide sets of related contexts for the relevant semantic areas - a far more useful source of vital semantic information than definitions, because contexts, whether verbal or cultural, contribute more to the meaning of a text than do the head-words of phrases" (178). Consequently, he proposes to abandon our Aristotelian heritage (i.e., the world is divided into perfectly structured categories) and start thinking in terms of fuzzy borders that are constantly being refined by language that is a behavioural activity. Grammar can also help translators overcome translation problems considering that lexical meaning cannot be viewed as a series of atomic units; rather, it is much more relevant to think in terms of tightly bound lexical units. Finally, mantras occur mainly in the speeches of politicians and the advertising of products.

Postcolonial approaches to translation are discussed by Tarek Shamma in "Postcolonial Studies and Translation Theory" (pp. 183-196). Postcolonial approaches examine intercultural encounters by exploring the symbolic connection between language and culture in contexts marked by unequal power relations, which obligue postcolonial translation scholars to deal with questions regarding the place where translation occurs, the personality of the translator(s), and the relationship between the languages and cultures involved. Some of these approaches tend to examine the role played by translation in indoctrinating the local people into the colonizers' worldview (Rafael 1993), 
whereas others focus on the reification of difference by abandoning ethnocentric universalism (Said 1993). In sum, postcolonial translation studies have contributed significantly to translation theory by investigating both actual (post) colonial interactions, and modes of analysis "that could illustrate crucial issues of identity, difference, and power" (p. 195).

The journal also includes reviews by Nuria Brufau Alvira, Aída Martínez-Gómez Gómez, Carles Biosca, and Anna Marzà i Ibànez (pp. 197-215). Brufau Alvira analyses Cronin’s Translation and Identity (2006), which develops the argument that translators and interpreters play a fundamental role in preventing human homogenization "from taking place as a consequence of globalization." Martínez-Gómez Gómez's review is concerned with Across Boundaries: International Perspectives on Translation Studies, a collection of papers edited by Kenny/Ryou (2007) that aims at proving that "the metaphor of translation as a border-crossing device can be widened and successfully applied to translation studies" (p. 202). Biosca examines Sociology of Translation, a collection of papers edited by Parada/Diaz Fouces (2006) that deals with the possibilities offered by analysing social factors in the field of Translation Studies. Finally, Marzà i Ibànez reviews Snell-Hornby's The Turn of Translation Studies (2006) that is devoted to offering Snell-Hornby's personal view of the history of translation.

\section{References}

Ahrenberg, Lars/Merkel, Magnus 2000: Correspondence Measures for MT Evaluation. In Proceedings of the Second International Conference on Linguistic Resources and Evaluation (LREC-2000). Athens, Greece, 1255-1261.

Bateson, Gregory 1972: Steps to an Ecology of Mind. Chicago: The University of Chicago Press.

Becker, Alton L. 2000: Beyond Translation: Essays Towards a Modern Philology. Ann Arbor: University of Michigan Press.

Chernov, Ghelly 2004: Inference and Anticipation in Simultaneous Interpreting. Edited with a critical foreword by Robin Setton and Adelina Ivanova. Amsterdam/Philadelphia: John Benjamins.

Cronin, Michael 2003: Translation ad Globalization. London: Routledge.

Cronin, Michael 2006: Across the Lines: Travel, Language, Translation. Cork: Cork University Press.

Cyrus, Lea 2006: Building a Resource for Studying Translation Shifts. In Proceedings of the Fifth International Conference on Linguistic Resources and Evaluation (LREC-2006). Genoa, Italy, 1240-1245.

Faber, P. C. Márquez Linares/Vega Expósito, M. 2005: Framing Terminology: A Process-Oriented Approach. Meta 50(4).

Faber, P. S. Montero Martínez/Castro Prieto, M. R./ Senso Ruiz, J. /Prieto Velasco, J. A./León Arauz, P./Márquez Linares, C./Vega Expósito, M. 2006: Process-oriented terminology management in the domain of Coastal Engineering. Terminology 12(2), 189-213.

Fernández González, Vicente (ed.) 2008: La traducción de la A a la Z. Córdoba: Berenice

Henitiuk, Valerie 1999: Translating Woman: Reading the female through the male. Meta 44 (3), 469-484.

Macken, Lieve 2007: Analysis of Translational Correspondence in View of Subsentential Alignment. In Proceedings of the METIS-II Workshop on New Approaches to Machine Traslation. Leuven, Belgium.

Mills, Sara 2008: Language and Sexism. Cambridge: CUP.

Newmark, Meter 1998, 2003: A Textbook of Translation. Essex: Longman

Rafael, Vicente L. 1993: Contracting Colonialism: Translation and Christian Conversion in Tagalog Society under Early Spanish Rule. Durham: Duke University Press.

Said, Edward. 1993: Culture and Imperialism. New York: Knopf.

Steiner, Frederick 1995: From Universing to Conversing: An Ecological Constructionist Approach to Learning and Multiple Description. In Steffe, Leslie/Gale, Jerry (eds.), Constructivism in Education. Hillsdale, NJ: Lawrence Erbaum, 67-84.

Velasco-Sacristán, Marisol/Fuertes-Olivera, Pedro A. 2006: Towards a critical cognitive-pragmatic approach to gender metaphors in Advertising English. In Journal of Pragmatics 38, 1982-2002.

Venuti, Lawrence 2008: Translation, Simulcra, Resistance. In Translation Studies 1(1), 18-33.

Pedro A. Fuertes-Olivera 
